\title{
Full-Scale Turbofan-Engine Turbine-Transfer Function Determination Using Three Internal Sensors - AIAA 2011-2912
}

\author{
Lennart S. Hultgren, NASA Glenn Research Center, Cleveland, OH 44135
}

\section{Summary}

Existing NASA/Honeywell EVNERT ${ }^{1}$ full-scale static engine test data is analyzed by using source-separation techniques in order to determine the turbine transfer of the currently sub-dominant combustor noise. The results are used to assess the combustor-noise prediction capability of the Aircraft Noise Prediction Program (ANOPP). ${ }^{2}$ Timeseries data from three sensors internal to the Honeywell TECH977 research engine is used in the analysis. The true combustor-noise turbine-transfer function is educed by utilizing a new three-signal approach. The resulting narrowband gain factors are compared with the corresponding constant values obtained from two empirical acoustic-turbine-loss formulas. ${ }^{3}$ It is found that a simplified Pratt \& Whitney formula agrees better with the experimental results for frequencies of practical importance. The $130^{\circ}$ downstream-direction far-field 1/3-octave SPL results of Hultgren \& Miles $^{4}$ are reexamined using a post-correction of their ANOPP predictions for both the total noise signature and the combustion-noise component. It is found that replacing the standard ANOPP turbine-attenuation function for combustion noise with the simplified Pratt \& Whitney formula clearly improves the predictions. It is recommended that the GECOR combustion-noise module in ANOPP be updated to allow for a user-selectable switch between the current transmission-loss model and the simplified Pratt \&Whitney formula.

The NASA Fundamental Aeronautics Program has the principal objective of overcoming today's national challenges in air transportation. The Subsonic Fixed Wing Project's Reduce-Perceived-Noise Technical Challenge aims to develop concepts and technologies to dramatically reduce the perceived aircraft noise outside of airport boundaries. The reduction of aircraft noise is critical to enabling the anticipated large increase in future air traffic.

\footnotetext{
${ }_{1}^{1}$ Weir, D. S. (editor), "Engine Validation of Noise and Emission Reduction Technology Phase I," NASA CR-2008-215225, 2008.

2 Zorumski, W. E., "Aircraft Noise Prediction Program Theoretical Manual," NASA TM-83199-Pt-1\&2,1982.

${ }^{3}$ Mahan, R. J. and Karchmer, A., "Combustion and Core Noise," Aeroacoustics of Fligh Vehicles: Theory and Practice, edited by H. H. Hubbard, Vol. 1, chap. 9, NASA Reference Publication 1258, WRDC Technical Report 90-3052, 1991, pp. $483-517$.

${ }^{4}$ Hultgren, L. S. and Miles, J. H., "Noise-Source Separation Using Internal and Far-Field Sensors for a Full-Scale Turbofan Engine," AIAA

Paper 2009-3220 (NASA TM-2009-215834), 15th AIAA/CEAS Aeroacoustics Conference, Miami, Florida, 2009
} 


\section{Full-Scale Turbofan-Engine Turbine-Transfer Function Determination Using Three Internal Sensors}

\section{Lennart S. Hultgren} NASA Glenn Research Center

Cleveland, OH 44135

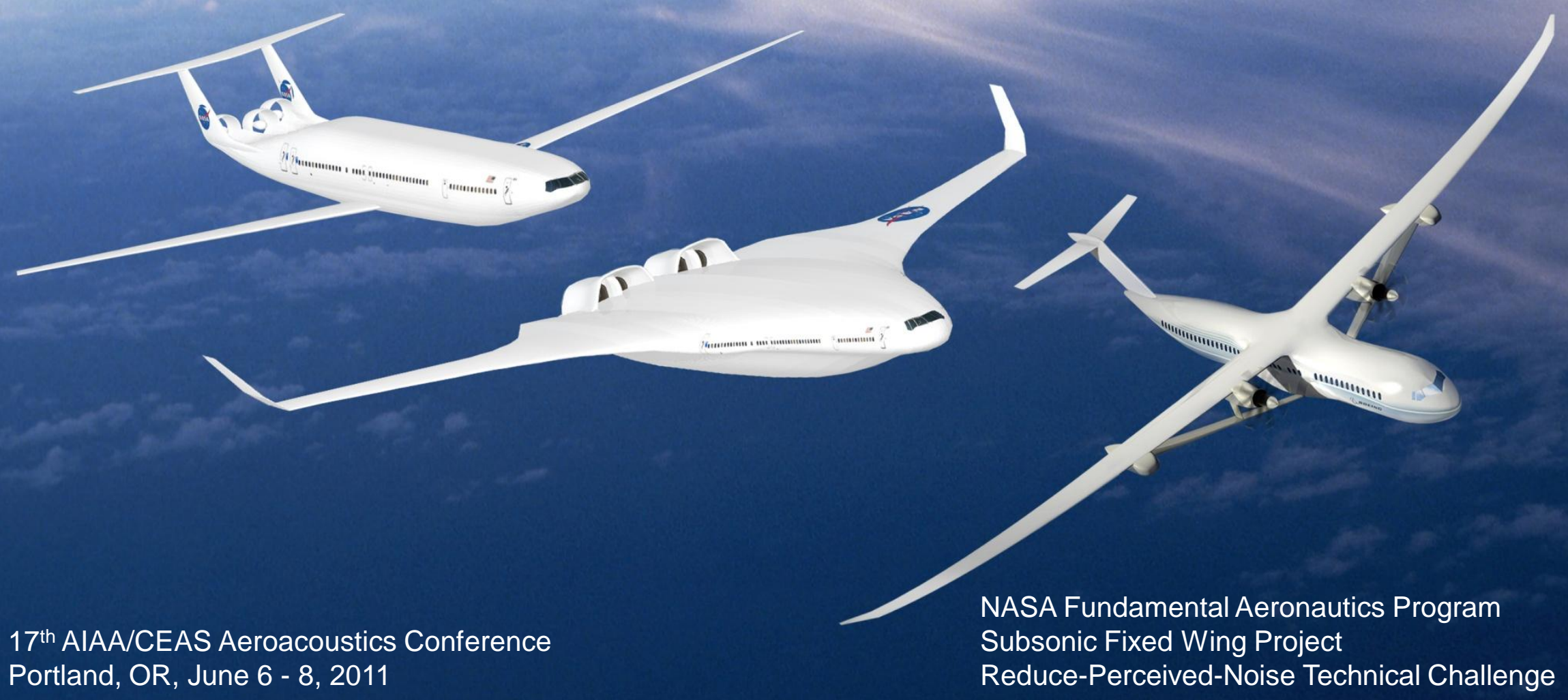




\section{Turbine-Transfer Function Determination}

\section{outline}

- Introduction

> NASA Subsonic Fixed Wing Project Goals \& Challenges

口 Turbofan design trends

> aeroacoustic implications

> emerging importance of core (combustor \& turbine) noise

> current noise-prediction tools based on 1970-80s technology

- Turbine-Transfer Function for Combustor Noise

> noise-source separation techniques applied to existing NASA/Honeywell EVNERT static-engine test data

๑ Summary \& Conclusions

> recommendation for ANOPP-module GECOR update

Improve aircraft noise-prediction capability and noise-reduction technologies 


\section{NASA FAP Subsonic Fixed Wing Project}

.... technology for dramatically improving noise, emissions, \& performance

a Principal objective of the NASA FAP is to overcome today's national challenges in air transportation

a Reduction of aircraft noise is critical for enabling the anticipated large increase in future air traffic

\ SFW Reduce-Perceived-Noise Technical Challenge

> enable concepts and technologies to dramatically reduce the perceived aircraft noise outside of airport boundaries

> present work is part of internal and sponsored-external research efforts for the development and improvement of aircraft noiseprediction capability and tools

- Turbofan core noise (combustor \& turbine) increasing in importance relative to other noise sources

Improve aircraft noise-prediction capability and noise-reduction technologies 


\section{Turbofan Design Trends}

.... overall cycle changes that will increase the relative importance of core noise

- Overall cycle changes:
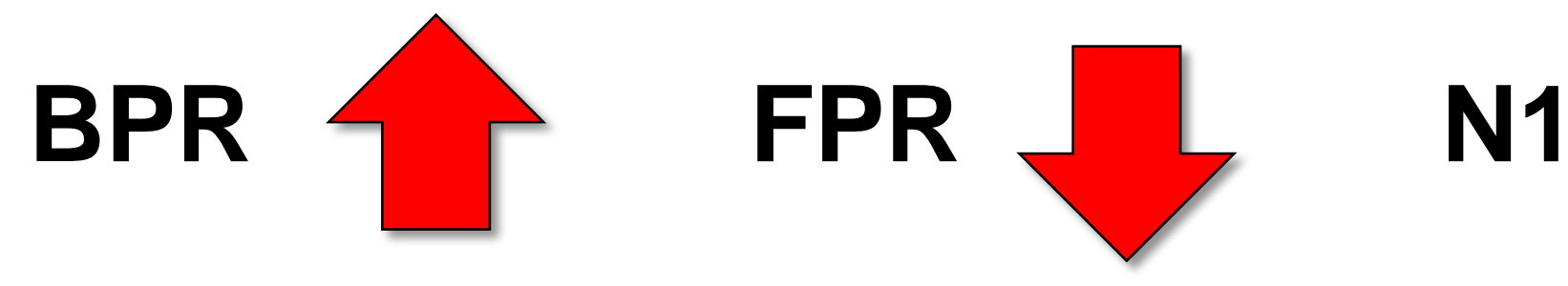

Non-core propulsion-noise components will be reduced at all power levels

- High-power-density, low-emission cores:

COMBUSTOR

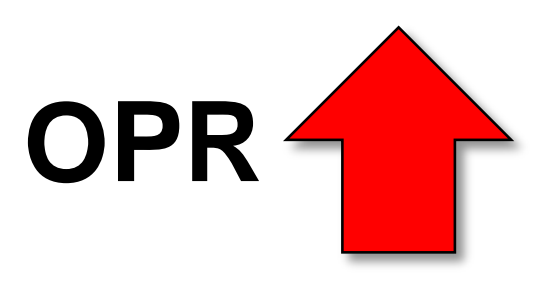

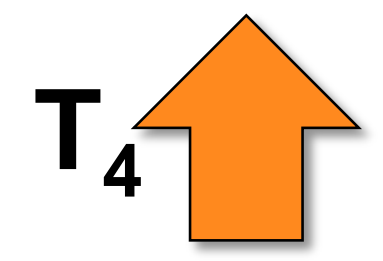

TURBINE (LPT)

Blade Loading

$\&$

Temperature
Blade Counts, Stages

$\&$

Stage Spacing

Core-noise components will be increased at all power levels 


\section{High-Power-Density, Low-Emission Cores}

... potential acoustic implications \& why core noise is important

- Core noise traditionally a concern only at approach, but ...

- Combustor noise increased due to

> direct noise increases with (OPR) ${ }^{2}$

> low-emission designs could increase indirect noise

> turbine design trends could lower transmission losses

> implications from near-combustion-instability operation

- Low-Pressure-Turbine noise increased due to

> stronger and more complex sources due to increased blade loading and decreased stage spacing

> less attenuation due to decreased stage solidities

> acoustic treatment more difficult due to increased temperatures

Emerging ultra-high-bypass-ratio engines with advanced high-powerdensity core components could make core noise a more significant component of the total engine noise signature at all power settings, which will need to be addressed to meet NASA noise goals 


\section{NASA FAP SFW Combustor-Noise Activities}

.... ongoing NASA in-house research efforts under Quiet-Aircraft Subproject

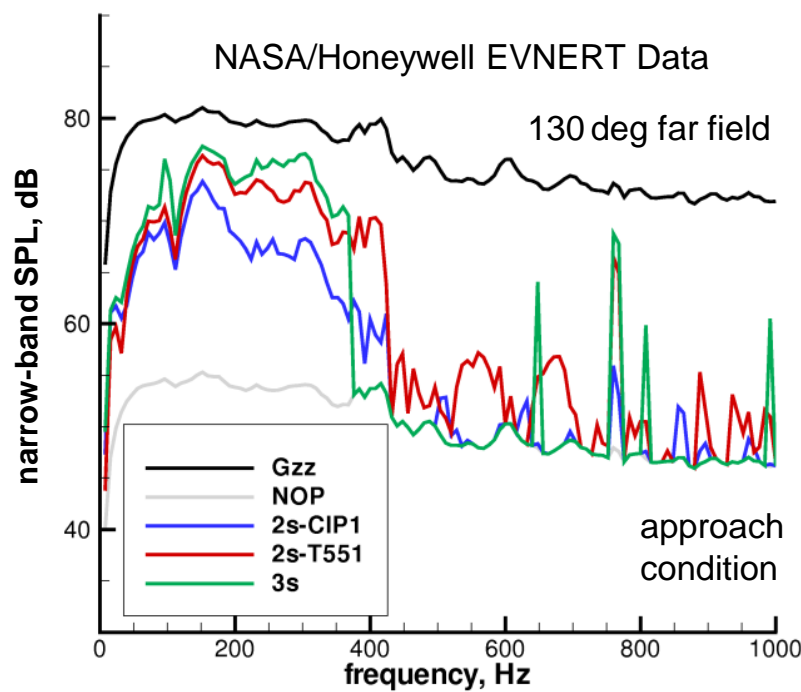

Honeywell TECH977 Turbofan

Sensors in aft fan High-temperature sensors bypass access panels with air cooling at turbine exit

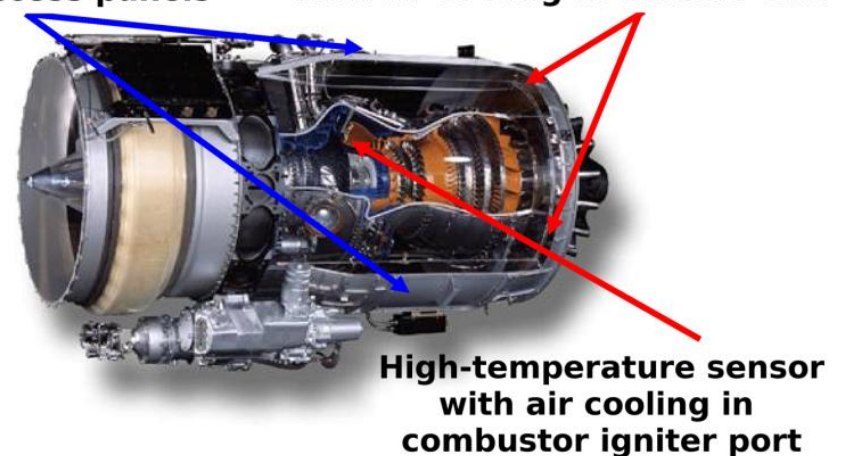

口 Presence of jet noise makes measurement difficult

> combustor noise masked by jet noise during static engine test

- Assessment and development of source separation methods

> necessary aid in developing improved reduced-order models

> applied to real engine data

$>$ aligned and unaligned coherence

J. H. Miles: AIAA 2006-0010

> new additional discriminator for three-signal method

L. S. Hultgren \& J. H. Miles: AIAA 2009-3220

> indirect combustor noise

Source-separation techniques applied to real-engine data to aid modeling 


\section{NASA FAP SFW Combustor-Noise Activities}

.... ongoing NASA in-house research efforts under Quiet-Aircraft Subproject
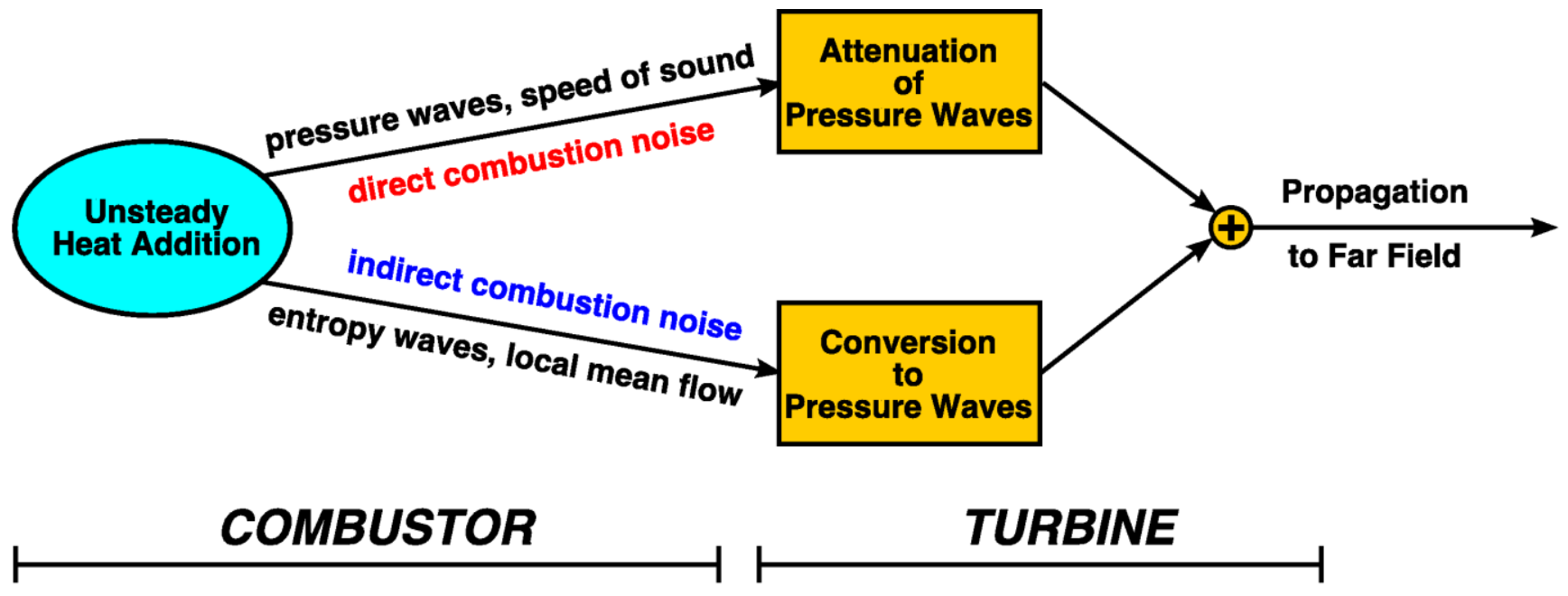

口 Direct and indirect contributions to combustor noise

- same low frequency range

r relative importance uncertain

- source-separation analysis: indirect noise present in real-engine data

J. H. Miles: AIAA 2008-0050; J. Propulsion and Power 25 (1), 2009;

J. Propulsion and Power 26 (2\&5), 2010

> in-house modeling and NRA high-fidelity LES study in progress

\section{Dual paths of combustor noise (direct \& indirect)}




\section{Diagnostic Techniques}

\section{applied to Honeywell TECH977 EVNERT data}

Honeywell TECH977 Turbofan

Sensors in aft fan bypass access panels

High-temperature sensors with air cooling at turbine exit
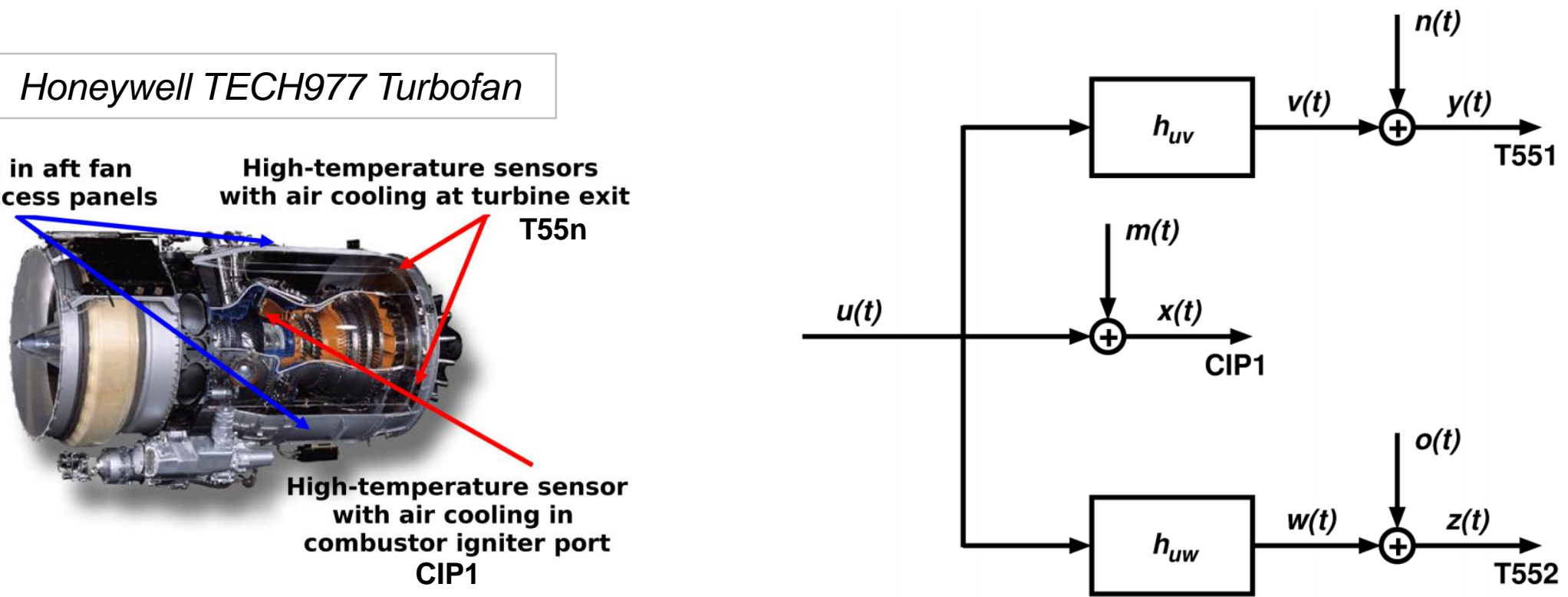

口 Three stations - CIP1: combustor; T551 \& T552: turbine exit

> $u(t), v(t) \& w(t)$ : coherent signals - not directly measurable

> $m(t), n(t) \& o(t)$ : mutually uncorrelated and uncorrelated with $u, v \& w$

> $x(t), y(t) \& z(t)$ : measurable signals

> goal is to determine one-sided auto spectra $G_{u u}(f), G_{v v}(f) \& G_{w w}(f)$ and frequency response functions $H_{u v}(f), H_{u w}(f), H_{v w}(f) \& H_{w v}(f)$

Engine-internal sensor arrangement and target 


\section{Combustor-Noise Turbine-Transfer Function}

\section{synopsis of theoretical results}

口 Two-signal approach

$H_{u v}(f)=H_{x y}(f)\left[1+N_{u}(f)\right]$

ignore

$N_{u}(f)=G_{m m}(f) / G_{u u}(f)$

> noise to signal ratio $N_{u}<<1$

$>$ assumption not likely true in practice

- 'true' gain underestimated by directly measured value, phase OK

a Three-signal approach

$$
\begin{array}{rr}
H_{u v}(f)=|1-\delta(f)| \frac{\left|G_{y z}(f)\right|}{\left|G_{x z}(f)\right|} \exp \left[\mathrm{i} \phi_{x y}(f)\right] & \phi_{x y}(f)=\arg G_{x y}(f) \\
\text { ignore } & \delta(f)=G_{n o}(f) / G_{y z}(f)
\end{array}
$$

$>$ measure of coherence of 'other' signals at turbine exit $|\delta| \ll<1$

> restriction more likely to hold in practice

Three-signal method needed for 'true' combustor-noise transfer function 


\section{Turbine Auto Spectra}

\section{turbine-exit narrowband (8 Hz) sound-pressure levels (SPL)}
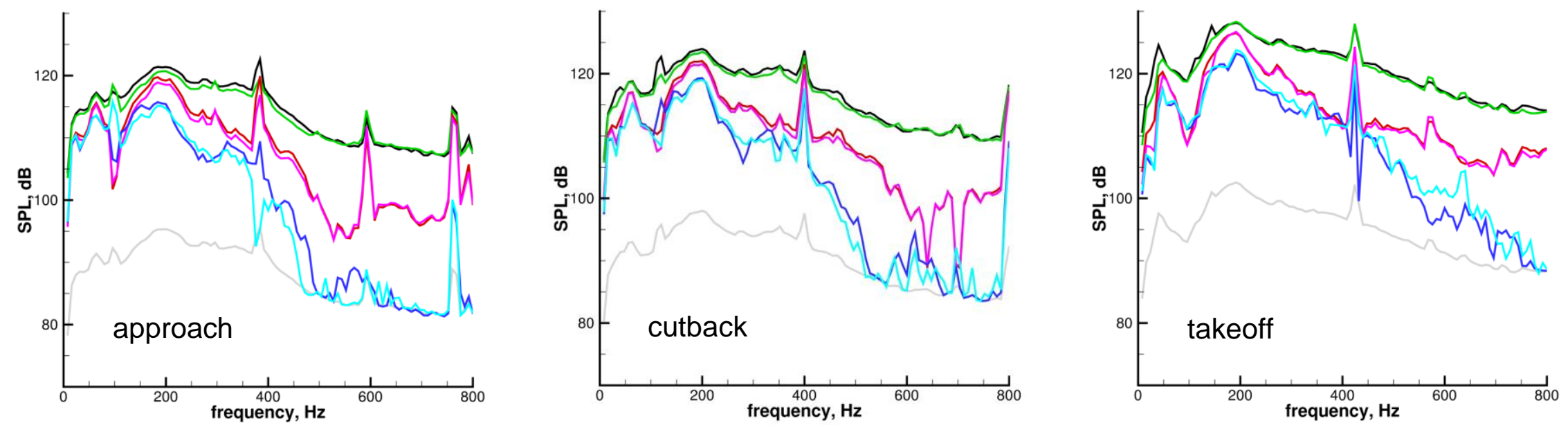

- Turbine-exit auto spectra

> total noise signatures $G_{y y}$ (T551) $G_{z z}$ (T552)

> turbine-internal coherent auto spectra $\gamma_{y z}^{2} G_{y y}$ and $\gamma_{y z}^{2} G_{z z}$

> combustor-turbine coherent auto spectra $\gamma_{x y}^{2} G_{y y}$ and

> two-signal method used

> coherence: $\gamma_{\alpha \beta}=\left|G_{\alpha \beta}\right| / \sqrt{G_{\alpha \alpha} G_{\beta \beta}}$

Coherent combustor noise present up to about $450 \mathrm{~Hz}$ at turbine exit 


\section{Turbine-Internal Transfer Function (T551 \& T552)}

\section{turbine-exit narrowband $(8 \mathrm{~Hz})$ gain and phase factors}
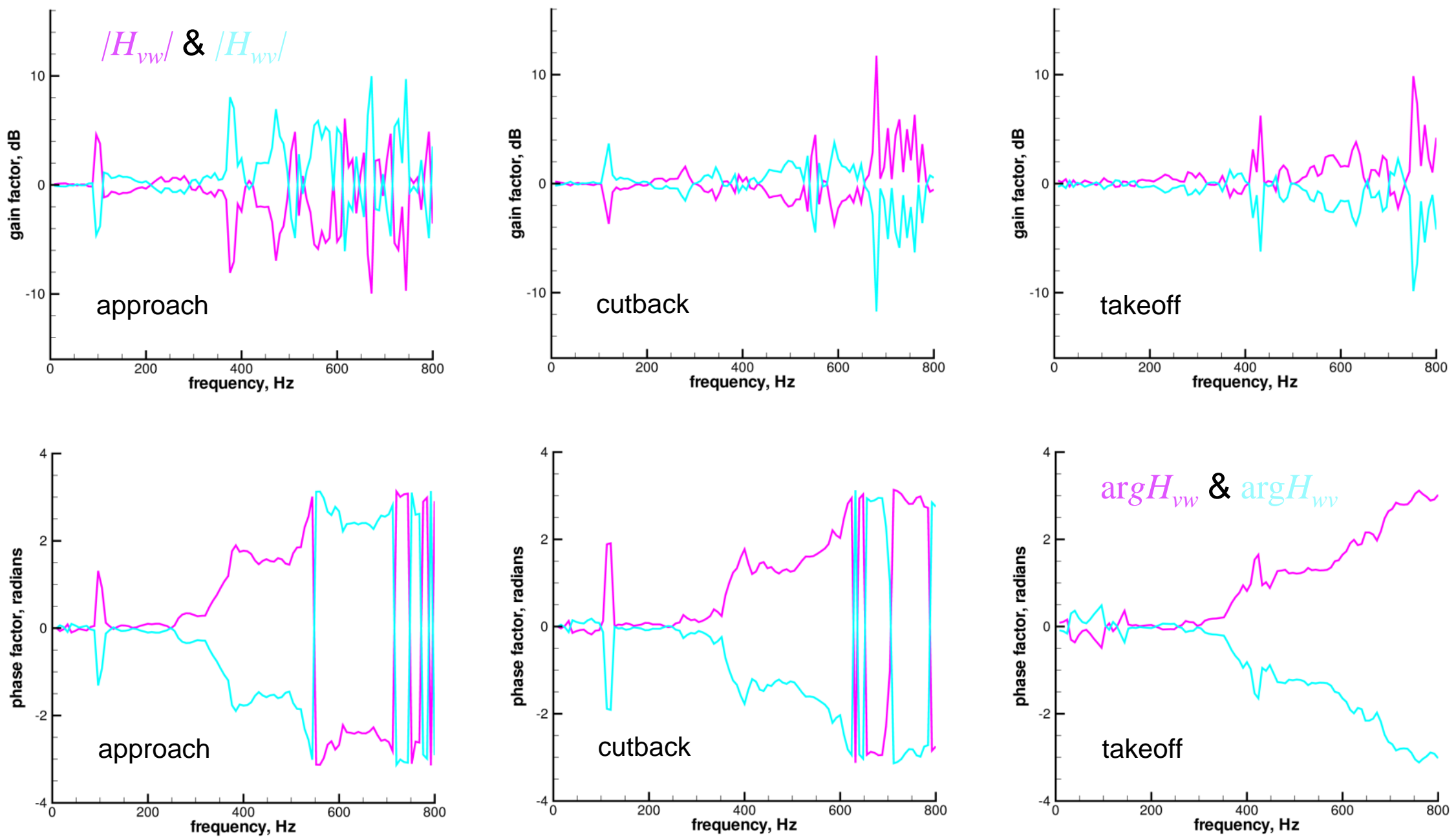

Unsteady pressure field dominated by plane waves up to about $350 \mathrm{~Hz}$ 


\section{Combustor-Noise Turbine Transfer Function}

\section{narrowband $(8 \mathrm{~Hz})$ gain factors}
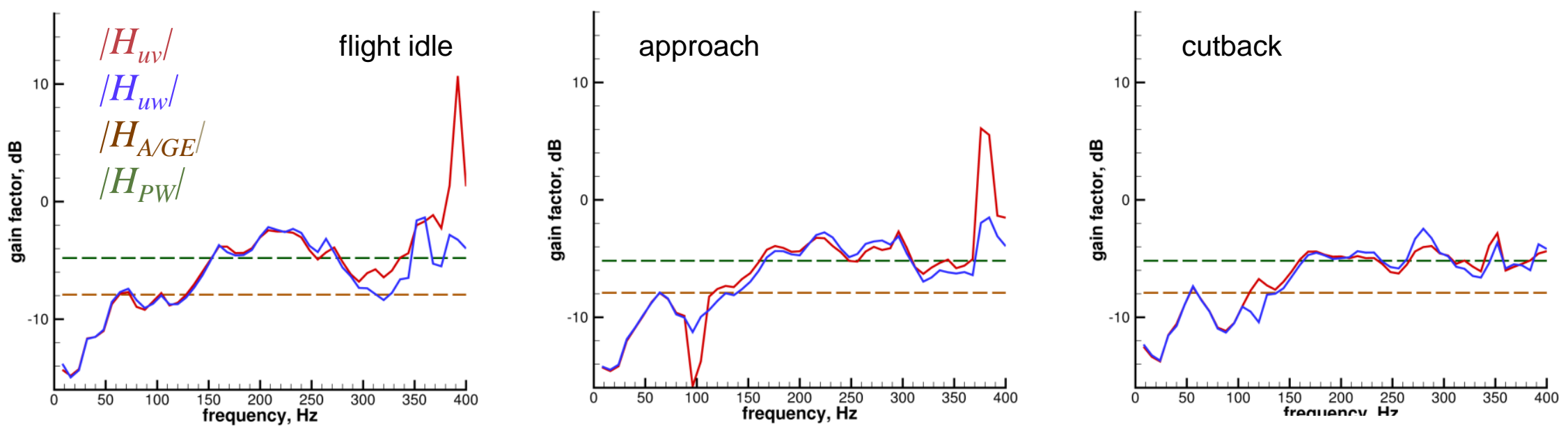

a Empirical turbine loss formulas

>ANOPP/GE: $\left|H(f)_{A / G E}\right|^{2}=\left(\Delta T_{\text {des }} / T_{\text {ref }}\right)^{-4}$

$\diamond \quad$ depends on design-point temperature drop

$\diamond$ independent of operating point

> Pratt \& Whitney:

\& simplified formula

$\diamond$ impedance ratio $\zeta=\rho_{t e} c_{t e} / \rho_{t i} c_{t i}$

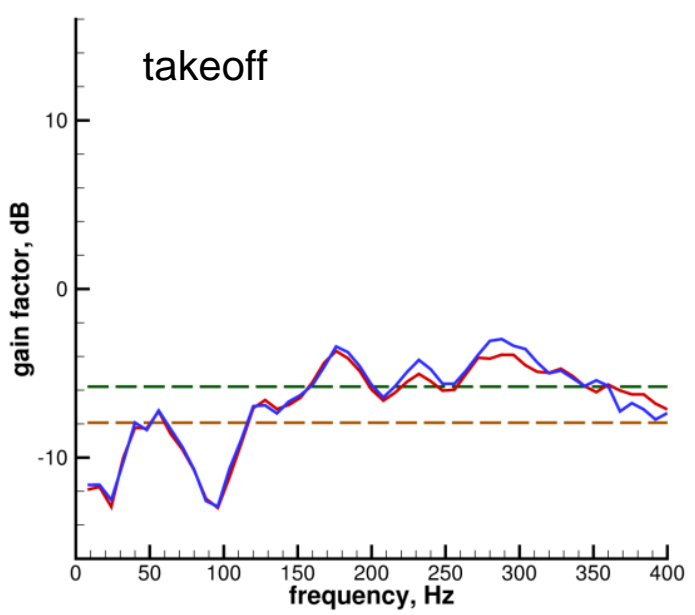

Simplified P\&W formula a better fit above $150 \mathrm{~Hz}$ (more significant region) 


\section{Degree Far-Field Comparison With ANOPP}

.... total and combustor-component 1/3-octave SPL
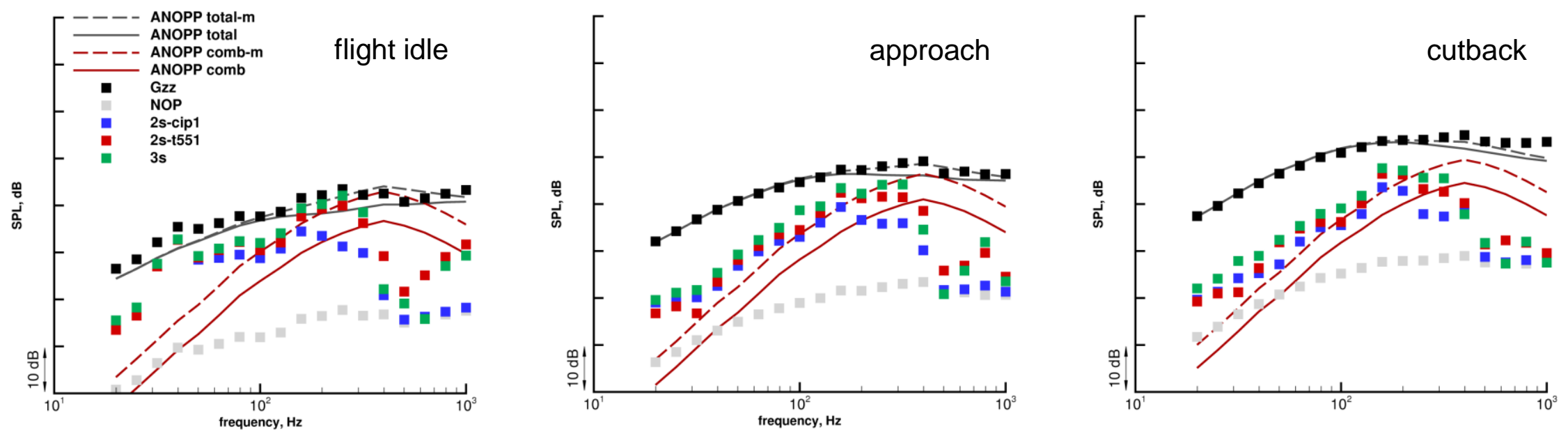

口 Based on Hultgren \& Miles 2009-3220

> they used three source-separation methods

> total and combustor component postcorrected to use simplified P\&W formula

> modified predictions are clear improvement

\& in particular for total noise signature

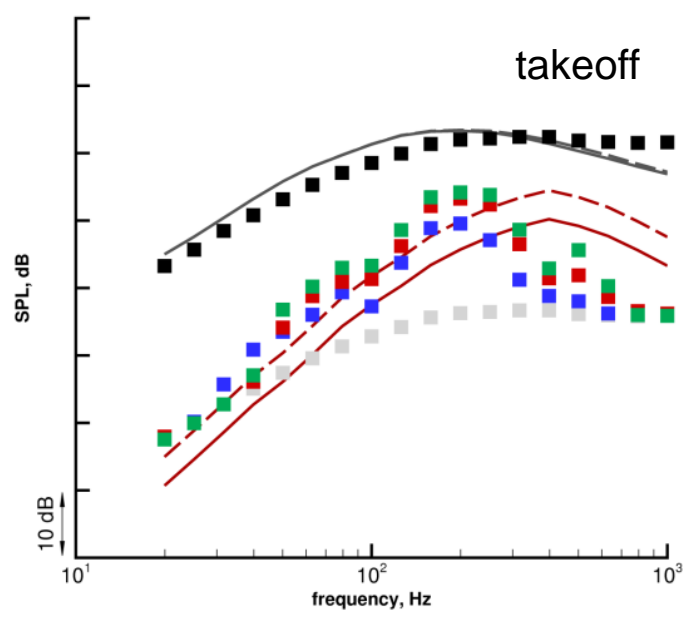

Substitution of simplified P\&W formula improves ANOPP predictions 


\section{Combustor-Noise Turbine Transfer Function}

.... effect of noise-to-signal ratio in combustor (8 Hz narrowband)

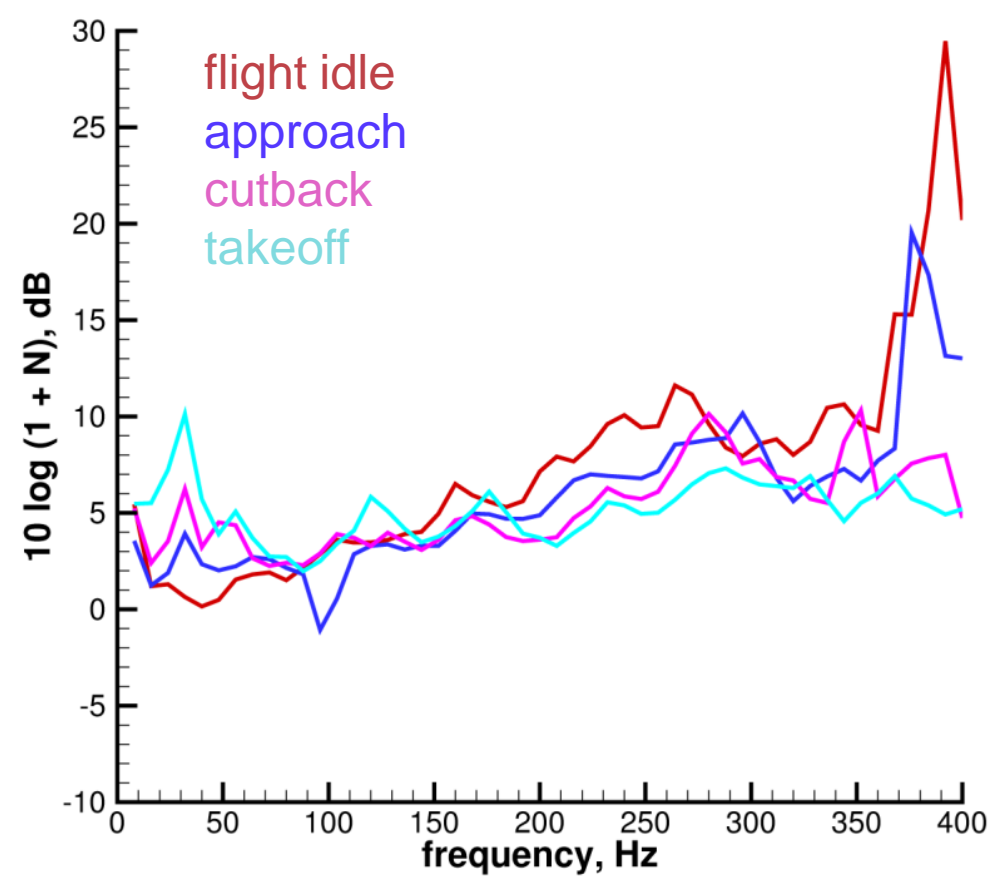

- Ratio of actual gain factor (three-signal method) to directly measured gain factor (two-signal method)

> error of using $H_{x y}$ as approximation for $H_{u v}$ clearly indicated

Three-signal method needed for 'true' combustor-noise transfer function 


\section{Summary \& Conclusions}

.... NASA FAP SFW Reduce-Perceived-Noise Technical Challenge

- Background

> existing prediction capability for core (combustor \& turbine) noise is based on empiricism

$>$ core noise needs to be addressed to meet noise goals

- NASA/Honeywell static-engine test data further analyzed

> 'true' combustor-noise turbine-transfer function determined

> new three-signal method essential to accomplish this

a Results compared to empirical formulas

- ANOPP/GE and simplified Pratt \& Whitney procedures

> simplified P\&W formula agrees better with educed gain factors

> post-corrected ANOPP far-field predictions using the simplified

P\&W procedure also agree better with 1/3-octave SPL data

- Recommendation

> update GECOR combustor-noise module in ANOPP to also allow usage of simplified $P \& W$ formula for turbine-transmission losses 
